\title{
AWARENESS REGARDING COMPLEMENTARY FEEDING AMONG MOTHERS IN A MUNICIPALITY OF NAWALPARASI DISTRICT, NEPAL
}

\author{
Sigma Bhattarai, ${ }^{1}$ Chet Kant Bhusal, ${ }^{2}$ Khima Shreesh ${ }^{3}$
}

\begin{abstract}
INTRODUCTION

Complementary feeding is key to promoting healthy growth and development, particularly during the first two years of a child's life. Lack of awareness and inappropriate feeding practices are a major cause of the onset of malnutrition in young children. The aim of the study was to find out the awareness regarding complementary feeding among mothers in a Municipality of Nawalparasi District, Nepal.
\end{abstract}

\section{MATERIAL AND METHODS}

Community based descriptive cross-sectional study was conducted to find out the awareness regarding complementary feeding among 67 mothers selected through non-probability convenient sampling technique. Data was collected by using semi-structured interview schedule and was analyzed by using descriptive (frequency, percentage, mean, standard deviation) and inferential statistics (chi square) with Statistical Package for Social Science software (SPSS) version 20.0. The total duration of the study was from September 5, 2018 to September 19, 2018

\section{RESULTS}

The findings of the study revealed that almost half $(47.8 \%)$ of the mothers had low level awareness regarding complementary feeding. There was no statistically significant association between respondents' level of awareness regarding complementary feeding and socio- demographic variables.

\section{CONCLUSION}

Based on the study findings, it is concluded that still half of the respondents had low awareness regarding complementary feeding. If all the mothers were aware regarding complementary feeding. They can prevent the consequences of undernutrition thereby enabling children to receive appropriate nutrition. Thus it would be recommended to concerned authority to conduct awareness program to mothers regarding complementary feeding.

KEYWORDS Awareness, Complementary feeding, Mothers.

1. Universal College of Nursing Sciences, UCMS, Bhairahawa, Nepal

2. Department of Community Medicine, Universal College of Medical Sciences, Bhairahawa, Nepal

3. Staff Nurse, Universal College of Medical Science, Bhairahawa, Nepal

DOI: http//doi.org/10.3126/jucms.v8i02.34307

\author{
For Correspondence \\ Ms. Sigma Bhattarai \\ Universal College of Nursing Sciences \\ UCMS \\ Bhairahawa, Nepal \\ Email: sigmabhattarai@gmail.com
}




\section{INTRODUCTION}

Complementary feeding is a process starting when breast milk alone is no longer sufficient to meet the nutritional requirements of infants, therefore other foods and liquids are needed, along with breast milk. ${ }^{1}$ The infants start receiving complementary foods at six months of age in addition to breast milk, initially two to three times a day between 6-8 months, increasing to three to four times daily between 9-11 months and 12-24 months with additional nutritious snacks offered one to two times per day, as desired. ${ }^{2}$

Globally in 2011, an approximately 101 million children under five years of age were underweight, 52 million were moderately or severely wasted, more than one quarter 165 million were stunted, 43 million were overweight due to inappropriate practice and lack of awareness of mothers regarding infant and young child feeding. In many developing countries, the incidence of under-nutrition usually increases during the period of complementary feeding from the age of 6 to 18 months. The occurrence of early nutritional deficits is linked to long-term impairments in child growth and health. ${ }^{4}$ The study of Nigeria showed that $14.9 \%$ of mother had low awareness regarding complementary feeding. About $72.1 \%$ of mothers knew that child should be breastfed on demand after starting on other feeds. ${ }^{4}$ Study of Ethiopia showed only $25 \%$ knew the correct time to start complementary feeding. ${ }^{5}$

Many innocent children suffer the curse of malnutrition; the responsibility goes to the mother, the family and to the community due to their faulty or no knowledge regarding benefits of exclusive breastfeeding and initiation of proper complementary feeding at the correct time. The study was thus conducted to find out the awareness regarding complementary feeding among mothers.

\section{MATERIAL AND METHODS}

Community based descriptive cross-sectional study was conducted in Pragatitol of Sunwal municipality ward number 1, Nawalparasi, Province -5, Nepal among mothers between $5^{\text {th }}$ of September to $19^{\text {th }}$ of September 2018. Mothers who have at least one child less than two years of age were included in the study.

Sample size was 67 mothers which was determined by using Slovin's formula $\mathrm{N}=\mathrm{N} / 1+\mathrm{N}(\mathrm{e})^{2}$ with $95 \%$ level of confidence interval, $10 \%$ margin of error, and total population of mothers having 2-year children $(\mathrm{N})=200$. Hence sample size $n=200 / 1+200(0.1)^{2}=67$. Non-probability convenient sampling technique was used to select the sample.

Face to face interview was carried out using pretested semistructured interview schedule for collecting data.The questionnaire was translated into Nepali and then retranslated into English and again into Nepali language to find misunderstanding and then correction was made.

Data checking, compiling and editing was performed manually by the researcher. Collected data were coded, entered and analysis was done by using Statistical Package for Social Science (SPSS) version 20.0 software package. Simple descriptive statistics such as frequencies, percentage, means and standard deviation were calculated and to finding association between the different variables in relation to the outcome variable was measured by chi-square test with $95 \%$ confidence interval.

\section{Ethical approval and consent to participate}

Research proposal was approved from Research Committee of Universal College of Nursing Sciences before data collection. Ethical approval was obtained from Institutional Review Committee of Universal College of Medical Sciences. Administrative approval was obtained from the concerned authority of Sunwal municipality of Nawalparsi. Written informed consent was obtained from each respondent by clarifying the objectives of the study.

\section{RESULTS}

Regarding socio-demographic variables mean age of respondent was 24.49 . Similarly, $83.50 \%$ of respondents were homemaker, all of respondents were literate. Likewise, $50.70 \%$ of respondents were from joint family, $56.70 \%$ of respondents had one child. Similarly, $38.80 \%$ of respondents had index child of age 19-24 months. Regarding respondents' awareness on meaning and initiation of complementary feeding $88.10 \%$ of respondents answered that meaning of complementary feeding as introduction of semi-solid and solid food along with breastfeed, similarly $79.10 \%$ of respondents answered six months of age as initiation of complementary feeding (Table 1).

Table 1. Respondents' awareness regarding meaning and initiation of complementary feeding $(n=67)$

\begin{tabular}{lcc}
\hline Variables & Frequency & Percentage \\
\hline Introduction of semi-solid and solid & 59 & 88.10 \\
food along with breastfeed* & 1 & 1.50 \\
Adding formula milk & 7 & 10.40 \\
$\quad$ Introduction of only semi-solid food & 7 & 10.40 \\
Initiation & 53 & 79.10 \\
5 months of age & 5 & 7.50 \\
6 months of age* & 2 & 3.00 \\
7 months of age & & \\
8 months of age &
\end{tabular}

With regards to awareness on types of complementary food all of the respondents answered grains and $47.80 \%$ answered 
eggs as types of complementary food. Similarly, all of the respondents answered prevent from malnutrition and $92.50 \%$ answered improve mental development and prevent from diseases as importance of complementary feeding (Table 2).

Table 2. Respondents' awareness regarding types of complementary food and importance of complementary feeding $(n=67)$

\begin{tabular}{lcc}
\hline Variables & \multicolumn{2}{c}{ Correct responses } \\
\hline Types of complementary food & 100 & Percentage \\
Grain & 60 & 100.00 \\
Legume & 32 & 89.60 \\
Egg & 60 & 47.80 \\
Fruits and vegetables & 35 & 89.60 \\
Dairy products & 45 & 52.20 \\
Fish and poultry & & 67.20 \\
Importance of complementary & 100 & \\
feeding & 66 & 100.00 \\
Prevent from malnutrition & 62 & 98.50 \\
Improve physical growth & 64 & 92.50 \\
Improve mental development & & 95.50 \\
Prevent from disease & & \\
\hline
\end{tabular}

Regarding respondents' awareness on frequency of complementary feeding, $35.82 \%$ of the respondents answered child between 6-8 months should be fed two to three times. Similarly, $70.20 \%$ of the respondents answered child between 9- 11 months should be fed three to four times. Likewise, $50.70 \%$ of the respondents answered a child between $12-24$ months should be fed three to four times with one to two time snacks (Table 3).

With regards to respondents' awareness on considerations for complementary feeding $19.40 \%$ of the respondents answered that number of meal during illness should be increased. Similarly, $23.90 \%$ of respondents answered both utensils and hand washing as precaution that should be taken before preparing food. Regarding proper way of feeding, $88.1 \%$ and $46.3 \%$ of the respondents answered tell kindly with love and offer a variety of soft food with different taste as proper way of feeding. (not shown in Table)

Table 3. Respondents' awareness regarding frequency of complementary feeding $(n=67)$

\begin{tabular}{lcc}
\hline Frequency of complementary feeding & Frequency & Percentage \\
\hline For child of age 6- 8 months & & \\
1 time & 23 & 34.33 \\
2-3 times* & 24 & 35.82 \\
4-5 times & 20 & 29.85 \\
For child of age 9- 11 months & 12 & \\
2 times & 47 & 77.90 \\
3-4 times* & 8 & 11.90 \\
5- 6 times & - & - \\
> 6 times & 2 & 3.00 \\
For child of age 12- 24 months & 34 & 50.70 \\
2 times with 1-2 time snacks & 30 & 44.80 \\
3- 4 times with 1-2 time snacks* & 1 & 1.50 \\
5- 6 times with 1-2 time snacks & & \\
> 6 times with 1-2 time snacks & & \\
*Correct response &
\end{tabular}

As regards respondents' overall awareness on complementary feeding, 52.2\% had high awareness and 47.8\% had low awareness. The total score of level of awareness was 23 and mean score was 14.47 (Table 4).

Table 4. Respondents' overall level of awareness regarding complementary feeding

\begin{tabular}{lcc}
\hline Level of awareness & Frequency & Percentage \\
\hline High $(=14.47)$ & 35 & 52.20 \\
Low $(<14.47)$ & 32 & 47.80 \\
Total & 67 & 100.00 \\
\hline
\end{tabular}

Table 5 represents the association between levels of awareness regarding complementary feeding with different independent variables. This indicates there is no relationship of these independent variables (age, occupation, types of family, age of index child and number of child) with respondents' level of awareness regarding complementary feeding.

Table 5. Association between respondents' level of awareness regarding complementary feeding and sociodemographic variables $(n=67)$

\begin{tabular}{|c|c|c|c|c|}
\hline \multirow[b]{2}{*}{ Variables } & \multicolumn{2}{|c|}{ Level of Awareness } & \multirow[b]{2}{*}{$\chi^{2}$} & \multirow[b]{2}{*}{$p$-value } \\
\hline & High $f(\%)$ & Low f $(\%)$ & & \\
\hline \multicolumn{5}{|l|}{ Age (in years) } \\
\hline $18-25$ & $23(56.09)$ & $18(43.90)$ & 0.631 & 0.427 \\
\hline $26-38$ & $12(46.15)$ & $14(53.85)$ & & \\
\hline \multicolumn{5}{|l|}{ Occupation } \\
\hline Formal & $2(100.00)$ & 0.00 & 2.653 & 0.103 \\
\hline Informal & $33(50.77)$ & $32(49.23)$ & & \\
\hline \multicolumn{5}{|l|}{ Type of family } \\
\hline Nuclear & $11(39.28)$ & $17(60.71)$ & 3.257 & 0.071 \\
\hline Joint and Extended & $24(61.54)$ & $15(38.46)$ & & \\
\hline \multicolumn{5}{|l|}{ Age of index child } \\
\hline 1 months - 12 months & $17(60.71)$ & $11(39.28)$ & 1.392 & 0.238 \\
\hline \multirow{2}{*}{\multicolumn{5}{|c|}{$\begin{array}{l}13 \text { months }-24 \text { months } \\
\text { Number of child }\end{array}$}} \\
\hline & & & & \\
\hline One & $22(57.89)$ & $16(42.11)$ & 1.128 & 0.288 \\
\hline More than and equal to 2 & $13(44.83)$ & $16(55.17)$ & & \\
\hline
\end{tabular}

Significance level at $p<0.05$

\section{DISCUSSION}

Nearly half of the respondents in the present study had low awareness level regarding complementary feeding. Different socio-demographic variables such as age, occupation, types of family, age of index child, number of children were not statistically significant with respondents' level of awareness. The present study revealed that $88.10 \%$ of respondents knew about the meaning of complementary feeding, however in contrast to this study another study conducted in Nigeria found lower portion of the respondents knew about the correct meaning of complementary feeding. ${ }^{4}$ This divergence might be due to different study setting and methodology adopted in two different studies. More than three-fourth of the respondents knew about age of initiation of complementary feeding as six months which is in line with another study conducted in Kathmandu, Nepal. ${ }^{6}$ Cent percentage of 
respondents in this study had awareness regarding grain as types of complementary food which is in line with another study conducted in Kathmandu, Nepal. ${ }^{7}$ Majority of the respondents in this study knew that legume is types of complementary food which is supported by the another study conducted in Kathmandu, Nepal. ${ }^{7}$ Nearly half of the respondents in this study knew that egg is type of complementary food, however this finding is not consistent with previous study conducted in Kathmandu, Nepal where more than four-fifth of respondents knew about same. ${ }^{7}$ This difference might be due to previous study was conducted in developed urban city. More than four-fifth of the respondents in this study knew that fruits and vegetables as types of complementary food which are not consistent with the previous study conducted in Kathmandu, Nepal where less than four-fifth of respondents knew that fruits and vegetables as types of complementary food. ${ }^{7}$ This differences might be due to different study setting.

More than half of the respondents in the present study knew that dairy product as types of complementary food which is not consistent with previous study conducted in Kathmandu, Nepal where majority of respondents knew that dairy product as types of complementary food. ${ }^{7}$ Two-third of the respondents knew that fish and poultry as types of complementary food which is not consistent with the study conducted in Kathmandu, Nepal where more than four-fifth of the respondents knew fish and poultry as types of complementary food. ${ }^{7}$ This differences might be due to different study setting.

The present study revealed that more than one-third of the respondents knew that a child between 6-8 months should be fed two to three times daily. However, another study conducted in Nigeria, showed lower portion of the respondents knew about the same. ${ }^{4}$ More than two-third of respondents knew a child between 9-11 months should be fed 34 times daily. This finding is not consistent with another study conducted in Nigeria, where less than half of respondents knew a child between 9-11 months should be fed at three to four times daily. ${ }^{4}$ More than half of the respondents in the present study knew a child between 12-24 months should be fed three to four times with one to two times snacks daily however another study conducted in Nigeria found nearly two-third of respondents knew a child between 12-24 months should be fed at three to four times with one to two times snacks daily. ${ }^{4}$ This divergence might be due to different study setting and methodology adopted in the studies. All the respondents in the present study were aware that complementary feeding support in prevention from malnutrition. The finding is consistent with the study conducted in Sri Lanka which showed majority of respondents were aware that complementary feeding helps in prevention from malnutrition. ${ }^{8}$ The present study revealed that majority of respondents were aware that complementary feeding improves mental development of child which is in line with another study conducted in Sri Lanka. ${ }^{8}$

More than one-fifth of respondents were aware that both utensils and hand washing as precaution that should be taken before preparing food, however another study conducted in Bangladesh found lower portion of respondents were aware both. ${ }^{9}$ The present study found that $88.10 \%$ and $46.30 \%$ of respondents knew that child should be talked kindly with love and offering a variety of food with different tastes and texture as proper way of feeding child respectively. The findings are not consistent with the study conducted in Sri Lanka where $98 \%$ and $91 \%$ of respondents knew child should be talked kindly with love and offering a variety of food with different tastes and texture as proper way of feeding child respectively. ${ }^{8}$ Nearly one-fifth of respondents were aware that number of meal during illness should be increased however, it is not consistent with the study conducted in Pakistan, where more than half of the respondents were aware that number of meal during illness should be increased. ${ }^{10}$

The sample size of the study was less and study was conducted in small setting. The study was conducted by using convenience sampling technique so that population representation of the study might be low. Therefore, external validity might be decreased. The findings of the study will be helpful to concerned authority, chief administrative officer of municipality to organize awareness program regarding complementary feeding. The findings of the study will be useful as baseline information for other researchers to conduct further research.

\section{CONCLUSION}

On the basis of findings of study, it is concluded that almost half of the respondents have low awareness regarding complementary feeding. Less than half of respondents know eggs as a type of complementary food. Likewise, less than two fifth of respondent know frequency of complementary feeding for child of age 6-8 months. There were no related factors for the level of awareness regarding complementary feeding among respondents. On the basis of findings of the study, the concerned authority of Sunwal municipality is recommended to conduct awareness program regarding complementary feeding among mothers having child less than two years and interventional study can be done to enhance the awareness among mothers.

\section{ACKNOWLEDGEMENT}

Researcher acknowledges the administration of UCMS-TH and Sunwal municipality of Nawalparsi District for providing 
necessary support during this study. Researcher deeply expresses their heartfelt thanks to all the mothers who participated in the study. Researcher also expresses their deep gratitude to all those experts for their valuable judgment, constructive feedback and enlightening suggestions throughout the study.

\section{CONFLICT OF INTEREST}

None

\section{REFERENCES}

1. World Health Organization. Infant and young child feeding; 2018.

2. World Health Organization. Complementary feeding: report of the global consultation, and summary of guiding principles for complementary feeding of the breastfed child; 2003.

3. United Nation Children's Fund. Improving child nutrition; the achievable imperative for global progress; 2013.

4. Olatona A, Adenihun JO, Aderibigbe A, Adeniyi OF Complementary feeding knowledge, practices, and dietary diversity among mothers of under-five children in an urban community in Lagos State, Nigeria Foluke. International Journal of MCH and AIDS. 2017;6(1):46-59.

5. Guled AR, Mamat BMN, Bakar AMAW, Assefa N, Balachew T. Knowledge, attitude and practice of mothers on infant and young child feeding in Shabelle zone, Somali region, Eastern Ethiopia. Revelation and Science. 2016;6(2):42-54.

6. Subedi N, Paudel S, Rana T, Poudyal AK. Infant and young child feeding practices in Chepang communities. Journal of Nepal Health Research Council. 2012;10(21):141-6.

7. Sapkota S, Shrestha S. Complementary feeding practices among the care takers of the young children at Nepal. Journal of Chitwan Medical College. 2013;3(4):25-29.

8. Seram SNV, Punchihewa PMG. Knowledge on complementary feeding among parents of children aged 4-12 months attending a base hospital in a rural district in Sri Lanka. Sri Lanka Journal of Child Health. 2017;46(2):139-147.

9. Sultana S, Hoque A, Saleh F. Infant and young child feeding practices and their nutritional status in a national nutrition programme area in Bangladesh. Journal of Human Nutrition and Food Science. 2014;2(2):1028.

10. Hasnain S, Majrooh AM, Anjum R. Knowledge and practices of mothers for complementary feeding in babies visiting pediatrics outpatient department of Jinnah hospital, Lahore. Biomedica. 2013;29(4):221-230. 